\title{
Note on Usage
}

In the pages that follow, all translations are my own unless otherwise indicated. I have anglicized the names of people and places, unless the forms in other languages are well known. I have retained original spellings in Latin and Romance vernacular quotations. I have transliterated Hebrew in accordance with the standards of the AJS Review. 



\section{Conversion,}

Circumcision, and Ritual Murder in Medieval Europe 
